\title{
The Proposed Method of using Plaster Nails for Fixing the Jouq Garden Monument Ceiling Painting Ornaments (Morteza Gholi Khan Egbalosaltaneh Palace, Sardar Maku)
}

\author{
Saeed Mehryar ${ }^{\star 1}$, Laleh Mahdi Nejad Asl ${ }^{2}$, Haleh Sanati Irani ${ }^{3}$, Sepideh Mehryar ${ }^{4}$ \\ ${ }^{1} M . A$ in Renewal and Restoration of Historical Buildings and Structures, Tabriz, IRAN \\ ${ }^{2}$ M.A in Architectural Engineering, Architectural Technology, Tabriz, IRAN \\ ${ }^{3}$ M.A in Islamic Art, Wooden arts, Tabriz, IRAN \\ ${ }^{4}$ B.A in Renewal and Restoration of Historical Buildings and Structures, Tabriz, IRAN
}

The method of using plaster nails for fixing the mansion of Morteza Gholi Khan Egbalosaltaneh, the commander of Maku, in Qajar period was purposed. These paintings are important for art researchers since it is the beginning of a kind of innovation in Iranian art in Gajar period (Fig.1). The western elements have been used in the interior design of the mansion and the execution of interior decorations such as the spaces colors and the most delicate arrangements in architectural ornamentations in terms of painting in the interior and exterior spaces (Table 1). The techniques of making painting layers in Qajar period have been employed in this monument which supporting layer, liners, the substrate and material layers are aligned with the same period historical houses resulted during the comparative studies (Fig.2). The damage to the decoration layers on the ceiling of the rooms that are unique in the subject matter is one of the most important damages to these ceilings, where the cracks are seen on the layer surfaces. Moreover, strengthening of the wooden support was accomplished by using a geo-grid mesh with the formation of a plaster board (Fig.3). First of all, there was a problem due to the sensitivity of the subject of restoration interference, simulation and prototype for the implementation of the proposal, in which the case study specimen was built in order to implement the proposed method using homogeneous materials with the historical value of the same period. In this way, the layers were arranged with reconstructing the lamellar layer, substrate layer and reinforcing the lining layer via galvanized hooks and wire for integration (Fig.4). The first step was the molding of the sample with the liners, substrates and supports layers (Fig.5). The next stage, reinforcement of the substrate and wooden support layers, was then performed exactly as the original (Fig.6). The plaster nail points were determined at defined intervals for influencing the level of layer engagement and holes were created from the bottom of the specimen to form a well-formed hole with a drill no. 12. The liner to substrate layers were evacuated using a drill bit with a diameter of $40 \mathrm{~mm}$ and a gimlet drill with $40 \mathrm{~mm}$ diameter (Fig.7). The gimlet drill penetration was done in depth of the substrate layer in two steps. At each step of drilling, the dusts were removed using air compressor. A chamber larger than the gimlet drill diameter was created cautiously in the interval of $10 \mathrm{~mm}$ from the supporting layer and the painting layer, in the depth of the substrate and the liner layers using a drill in $35 \mathrm{~mm}$ diameter. This chamber was created for better bonding of plaster nails in a broad scope. For more connection of the plaster nail and also creating a broad network and transfer of load bearing in the liners and substrate layers on the plaster

\footnotetext{
*Corresponding author: saeedmehryar@gmail.com
} 
board layer, the holes with a 45 degree angle to the vertical hole of the plaster chamber were created (Fig. 8). In order to create a plaster nail, before pouring sharp plaster with a diluted solution of Pelexitol glue $(10 \%)$ in the created chamber, the plaster nail reinforcement was used by galvanized wire to connect the plaster nails to the joists of wooden beams as the most important points (Fig.9). Due to the fact that in the later stages, the implemented specimens showed a better performance with the color differences from the reinforced plasterboard, substrate and liner layers, plastering was done using pigmented plaster in a different color. The plaster used in a smaller amount, was poured into the heeltap compartment with a solution of Pelexitol glue (10\%) in stages. At this stage, a throbbing was performed using sequestering in the plaster slurry. Failure to create a seismic during the grouting causes bubbles in the plaster nail, which is one of the disadvantages of this method (Fig.10). In the final stage, after the creation of the plaster nails, a simulated specimen was cut from the middle portion in order to show the performance of the plaster nails and the amount of penetration in the substrate and the liner layers (Fig.11). 


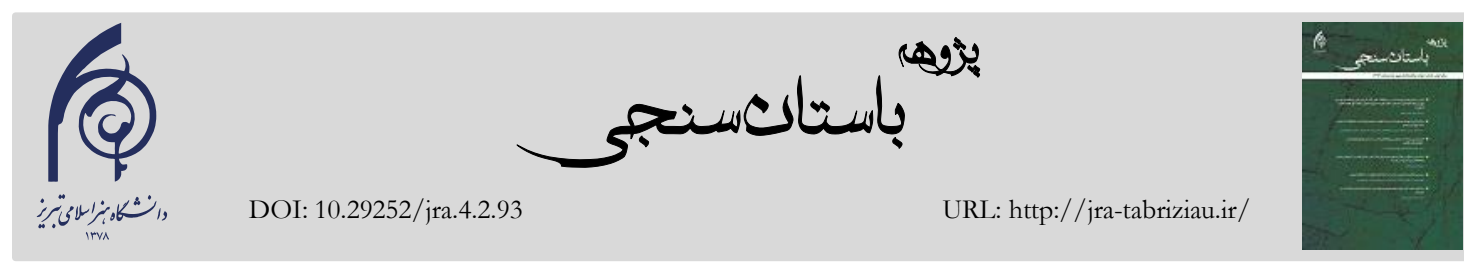

يادداشت فنى

\title{
(1)
}

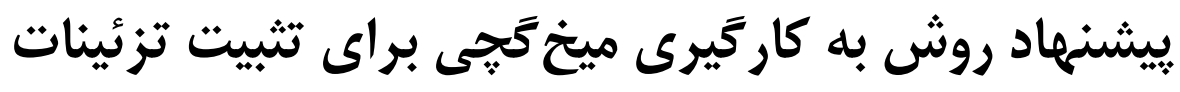

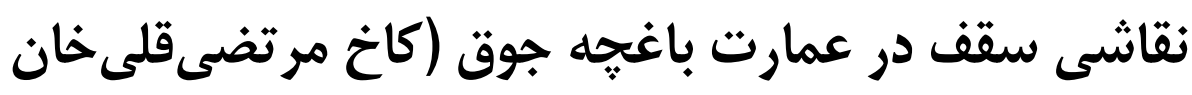

\section{اقبال السلطنه سردار ماكو)}

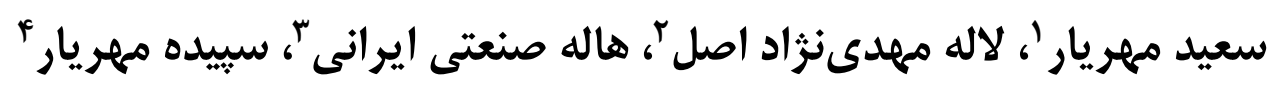

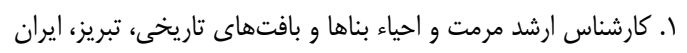

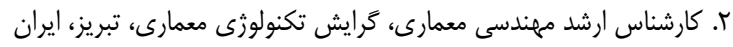

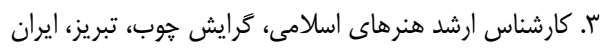

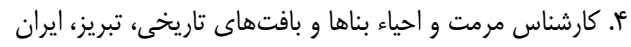

Iس تاريخ يَيرش:

تاريخ دريافت: INQV/

استـفاده از فضاهاى يُروخالى، كاربرد در نماها و جدارهها از تكنيكهاى آراستن از موتيفهاى قفقازى و شرق آناتولى

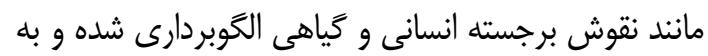

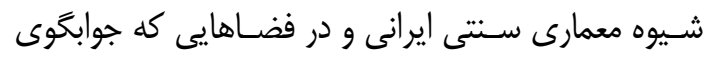
روح ايرانى اسـت، استفاده كَرديده است. اقبال السلطنه به به فيه واسـطه سـفرهايى كه به فرنخ داشتهاست، اقلام و موارد


كه در تكامل اين شـيوه زندگى در فضاى معمارى عمارت

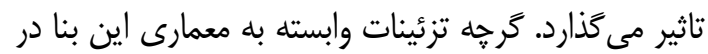
طى دهلهاى كذشـته متحمل آسيب فراوان شدهاست، اما نمونههاى باقيمانده به لحاظ مصالح بومشناختى در شكل و فرم، داراى نمونههاى منحصـربافررد تقابل سنت و مدرنيته

است (شكل ().
ســـر آمد عمارت هاى منطقه خان نشـــين ماكو به تحقيق يزوهشـــران، كاخ مرتضـى قلى خان اقبال السـلطنه، سردار

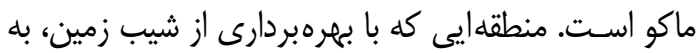
صورت باغ مُطبق، گستره ايى در جهت شرقى -غربى بـ دئ دارد. بنـاى عمارت باغته جوق در حوزه مطالعات معمارى حاكم بر منطقه ماكو در دوران قاجاريه، از جمله بناهايى است كه به به صورت كوشك در محوطه باغ تاريخى با مسطح نمودن عوارض طبيعى شيب دامنه آبرفتى اين كوهها، باغ بلهصورت

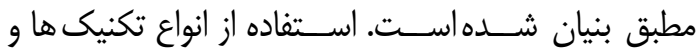



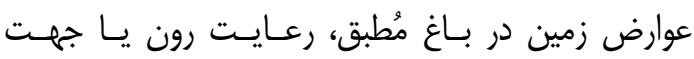
عمارتسازى در باغ، صفهسازى، استفاده از مصالح بومآورد،

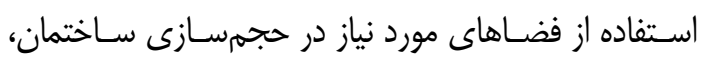

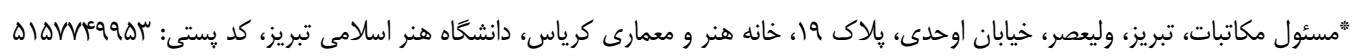

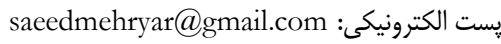

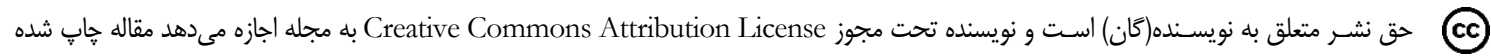
را با ديخران به اشتراك بكذارد منوط بر اينكه حقوق مؤلف اثر حفظ و بهن به انتشار اوليه مقاله در اين مجله اشاره شود. 


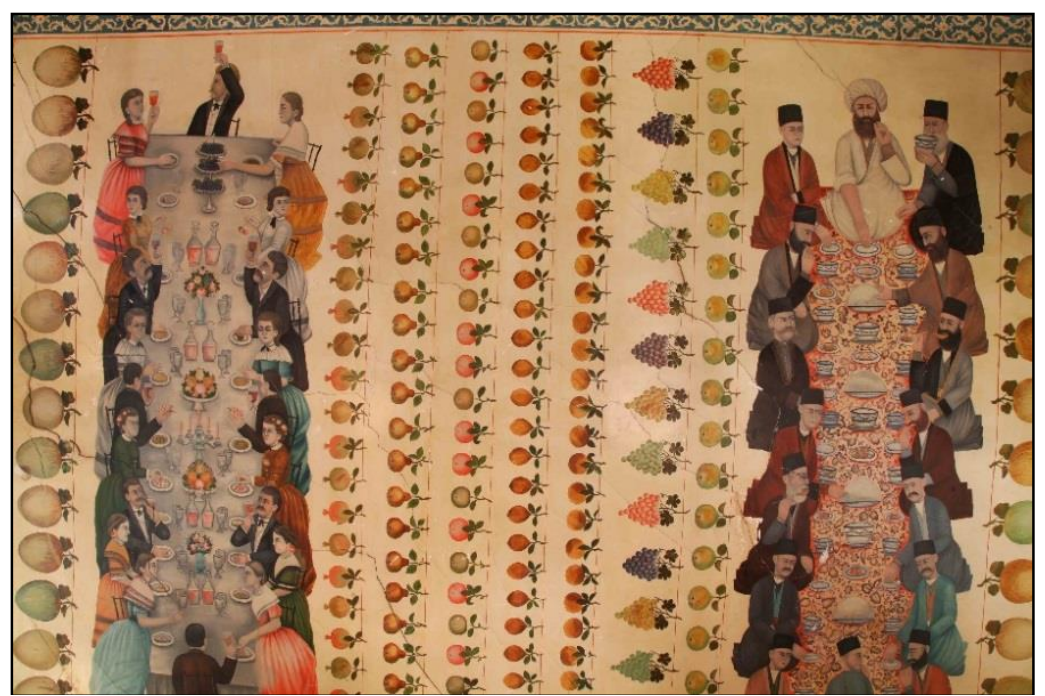

شكل ا: نقاشىهاى سقف اتاق سفرهخانه كه آسيبهاى ترك، طبله باعث جدايى لايه اجرايى گرديده است

Fig. 1: Paintings of the ceiling of the dining room, which caused the cracks damage leading to separation of the implemented layer

نقش هـا اجرا كَرديـده اســت. اســتفــاده از تكنيكى رايج

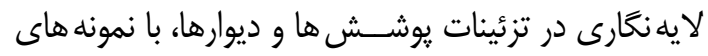
موردى در منطقه آذربايجان با مطالعات تطبيقى همســان

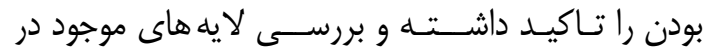
عمارتها و خانههاى تاريخى منطقه، اين موضـوع را تاييدان مى نمايد. تكنيك هاى سـاخت لايه هاى نقاشـى تارئ در دوره قـاجار با ايجاد لايه تكيه كاه، لايه بســتر، آســتر و لايه لايه

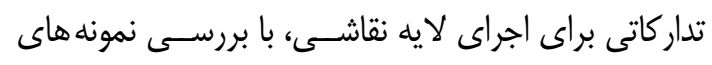

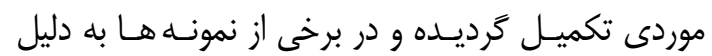


تفاوتها وجود دارد.
از انواع عناصــر فرنخى در طراحى فضــاهاى داخلى

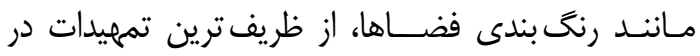

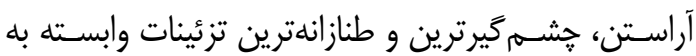
معمارى به لحاظ رنخَنغارى در تزئينات، در فضــاهاى بيرونى و اندرونى استفاده گرديده است (جدول (). در نماها

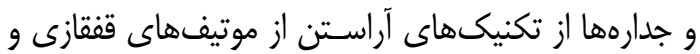

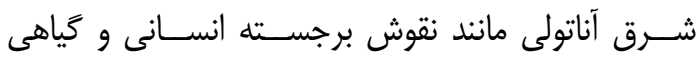

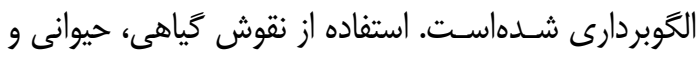
انسـانى در تزئينات نقاشى عمارت، با توجه به آب و هواى حئ منطقه ييلاقنشـين، اين مسئله را روشن مى سازد كه انواع

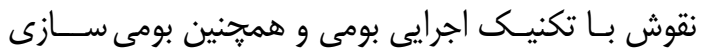

جدول ا: تزئينات وابسته به معمارى در عمارت سردار ماكو

Table 1: Architectural decoration in the Sardar Maku Mansion.

\begin{tabular}{|c|c|c|c|c|c|c|c|c|c|}
\hline $\begin{array}{c}\text { صدف جينى } \\
\text { Uniform } \\
\text { snail } \\
\text { shellfish }\end{array}$ & $\begin{array}{c}\text { آيينه كارى } \\
\text { Decoration } \\
\text { with mirror }\end{array}$ & $\begin{array}{c}\text { خوب } \\
\text { Wood }\end{array}$ & $\begin{array}{l}\text { كاشيكارى } \\
\text { Tilework }\end{array}$ & $\begin{array}{c}\text { سنگ } \\
\text { Rubble } \\
\text { with } \\
\text { binding } \\
\text { material }\end{array}$ & گَجبرى رنغى & $\begin{array}{c}\text { گُجبرى نقش برجسته } \\
\text { Stucco } \\
\text { relief }\end{array}$ & $\begin{array}{l}\text { مجسمه } \\
\text { Statue }\end{array}$ & $\begin{array}{c}\text { نقاشى } \\
\text { Painting }\end{array}$ & $\begin{array}{c}\text { موقعيت } \\
\text { Location }\end{array}$ \\
\hline * & - & * & - & * & * & * & * & - & $\begin{array}{c}\text { ن } \\
\text { Façade } \\
\text { mode }\end{array}$ \\
\hline- & * & * & * & * & * & * & * & * & $\begin{array}{c}\text { فضاى داخلى } \\
\text { Internal } \\
\text { space }\end{array}$ \\
\hline
\end{tabular}




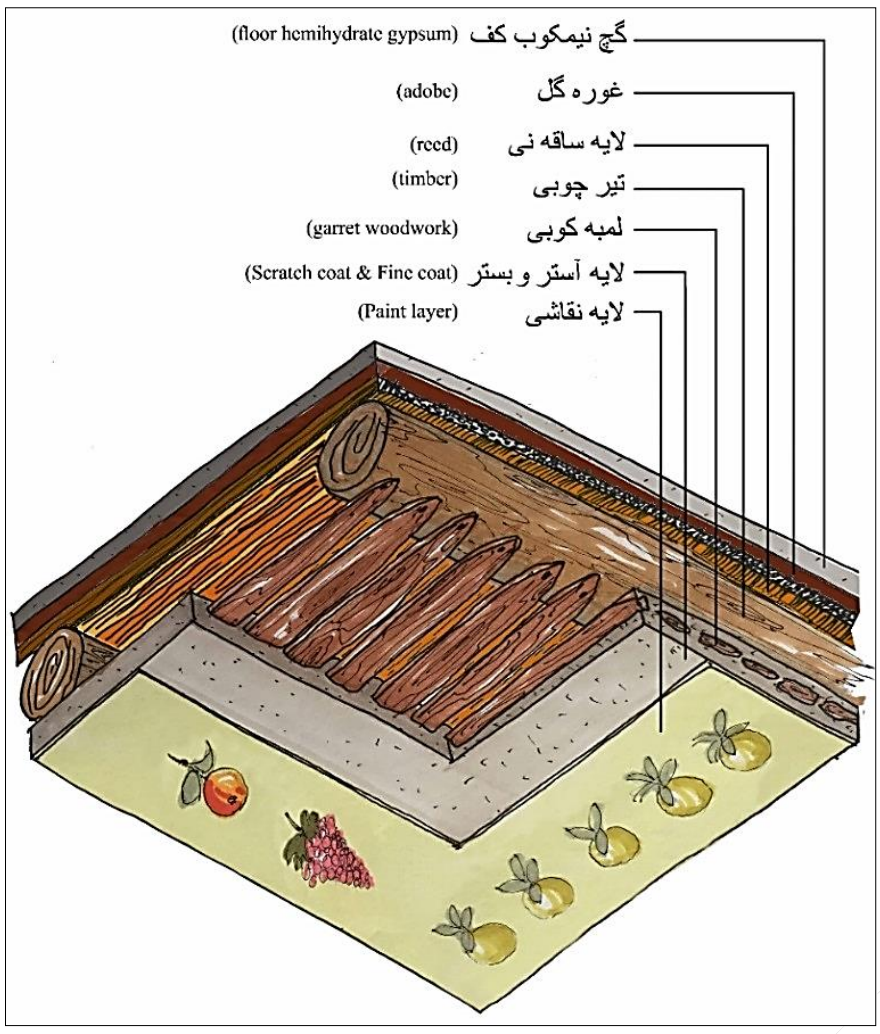

شكل ז: طرح كلى لايه هاى اجرايى براى يوشش سقف

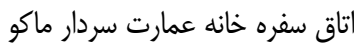
Fig. 2: The layout of the layers for covering the ceiling of dining room in the Sardar Maku Mansion

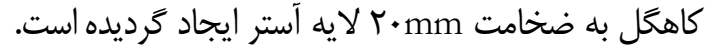

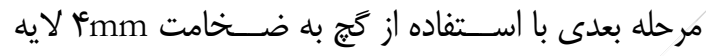
تدار كاتى گسترده شده و در نهايت لايه نقاشى بر روى بل اين

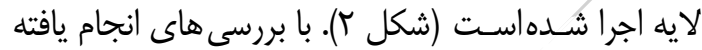

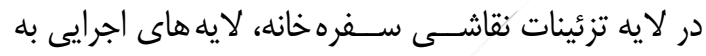

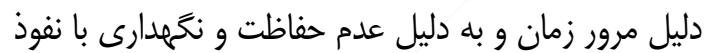

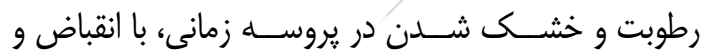



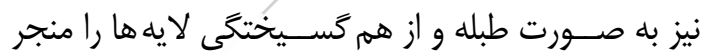

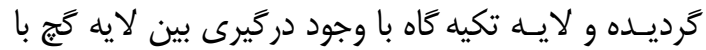

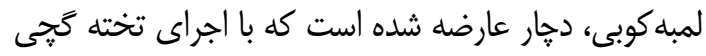

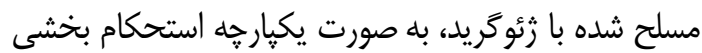

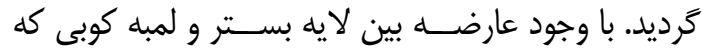
منجر به سـسـت شـدن و در نقاطى باعث جدايى لايه ها شـده بود، ابتدا ســـح بالاى يوشش كه به صورت جزئئيات

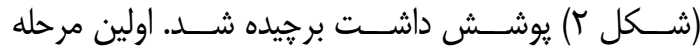

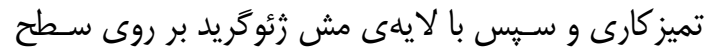
تيرهاى جوبى و لمبه با اسـتفاده از ميخ دويايهايى كالوانيزه



در برخى از اين نمونه ها، لايه آسـتر با استفاده از كاه گَل و

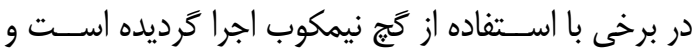
تفاوت اجرايى در مرحله اجراى اين مصالح در آستر و بستر نمايش داده شدهاست. نقش هاى موجود در اتاق سفرهخانه از بديع ترين نمونه هاى موردى نقاشــى در نمايش تقابل

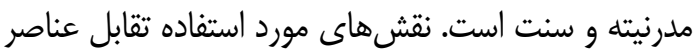
فرهنَ غربى را در فرهنَ ســنتى نمايش داده، و مفهوم

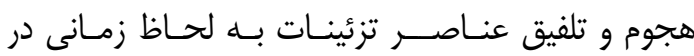

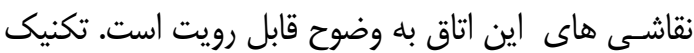

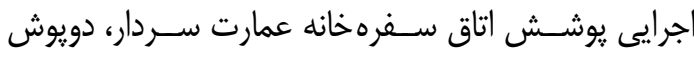

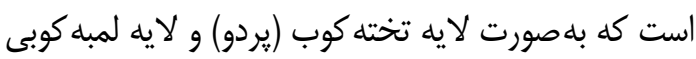

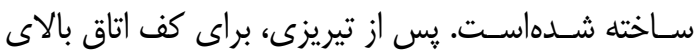

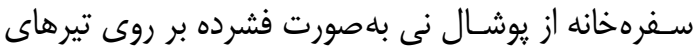
جوبى جهت همسـان سازى استفاده شدهاست، بر روى اين

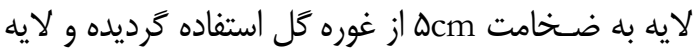
مسـطح با استفاده از گج نيمكوب انجام يافته است. يس از لمبل كوبى بر روى تيرهاى جوبى(تكيه كاه جوبى) با استفاده از گج نيمكوب لايه بسـتر به ضخامت mm ها به لمبلها اتصـال داده شــدهاسـت. بر روى لايه بسـتر با اسـتفاده از 
شـبيه سـازى، و رسيدن به طرح مرمت اجرا شده و الخوى اجرايى، احتمال اجراى غلط در اتصــال لايههاى موجود را

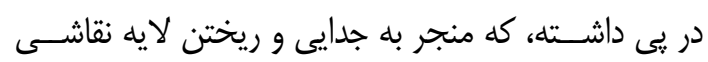
خواهدشد. براى مرمت و استحكامبخشى لايههاى تزئينات

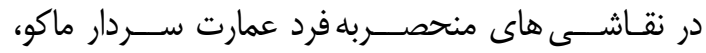


موردى با مواد و مصـالح موجود، با ارزش تاريخى همدوره با مصـالح عمارت سردار ماكو تهيه كرديد. تكنيك اجرايى بخش انتخاب شـــه در طرح مرمت ييشــنهادى ســازمان ميراث فرهنكى به صـورت نوسـازى در نظركرفته شده بود كه قرار بر تخريب بخش مورد انتخاب شده بود و از سقف بـ

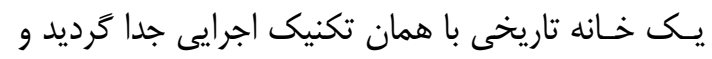

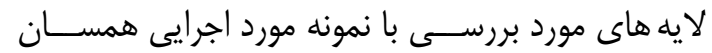

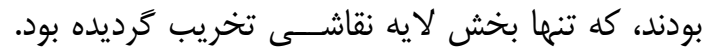

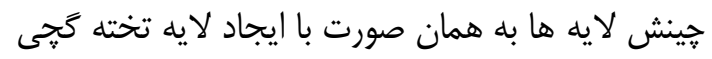

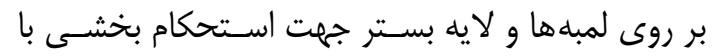

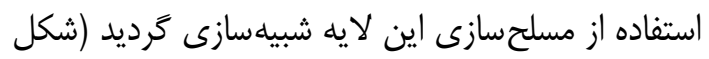

اختلاط نصــف به نصــف، كج تيز تهيه كرديد. اين لايه

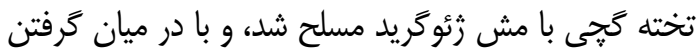

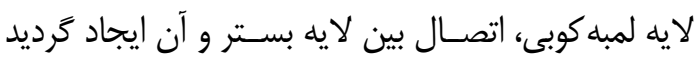



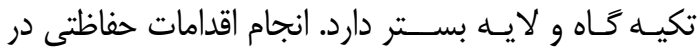

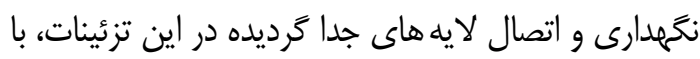
وجود نقاشى هاى نفيس و منحصربهفرد مشكل را دوجندان

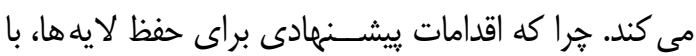

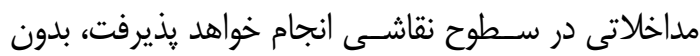
مسـتندنكارى و همســان ســازى بخش هاى مورد اسـتفاده براى ايجاد ميخ كَّى -براى ييشنهاد حفاظتى - با تيرهاى



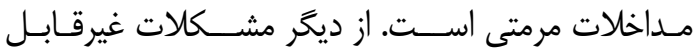

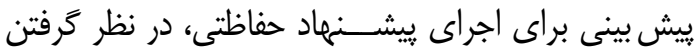

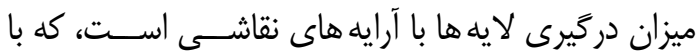
وجود عارضـههاى ترك و طبله در طى سـال هاى كذشتهاه،

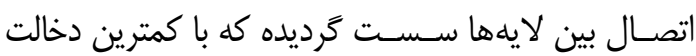

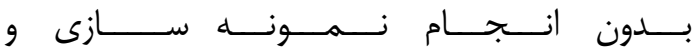

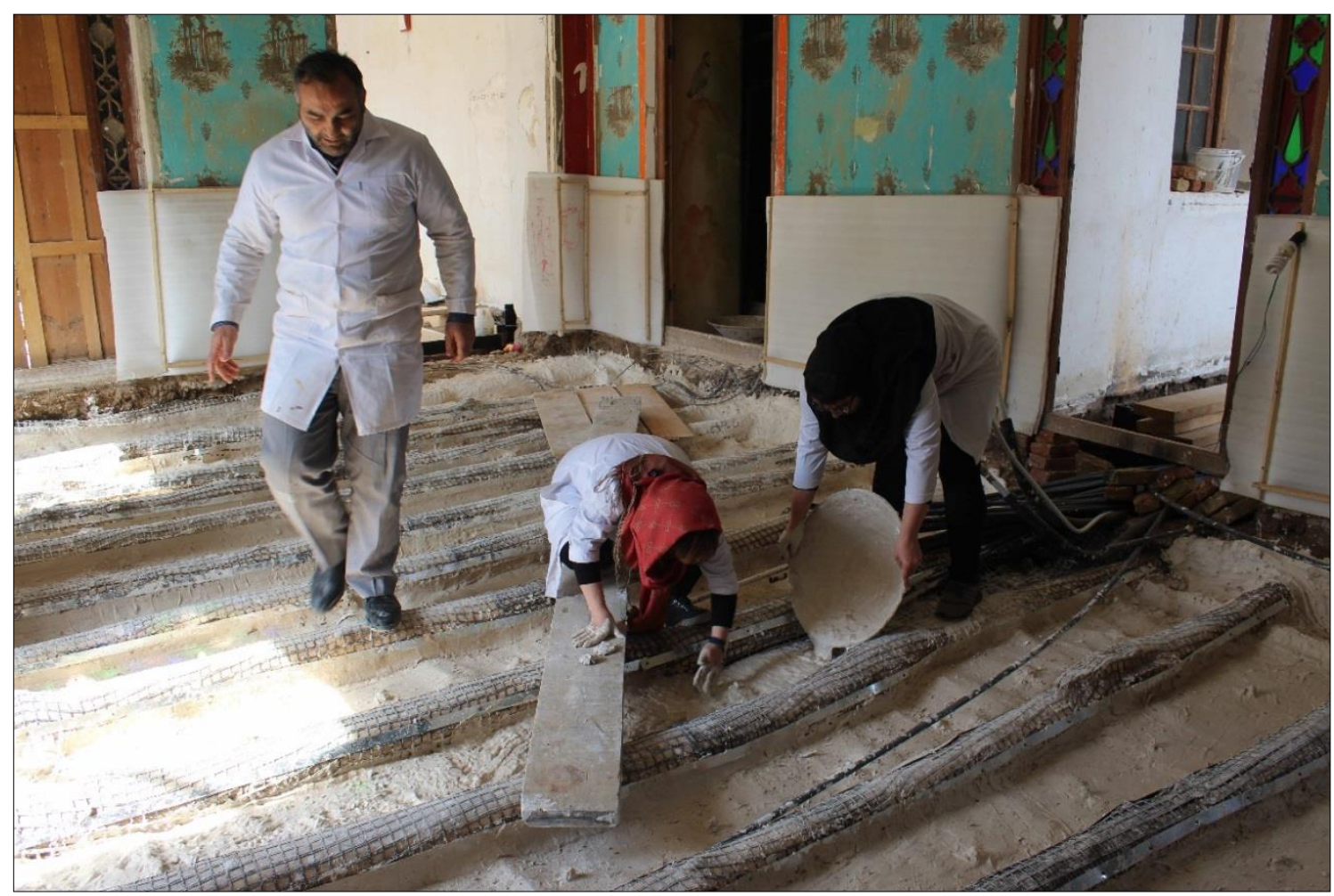

شكل "ا: اجراى تخته كَّى در بين تيريوش هاى سقف اتاق سفرهخانه عمارت سردار ماكو

Fig. 3: Implementation of plaster boards in the ceiling of the dining room beams in the Sardar Maku Mansion

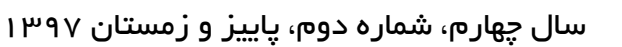




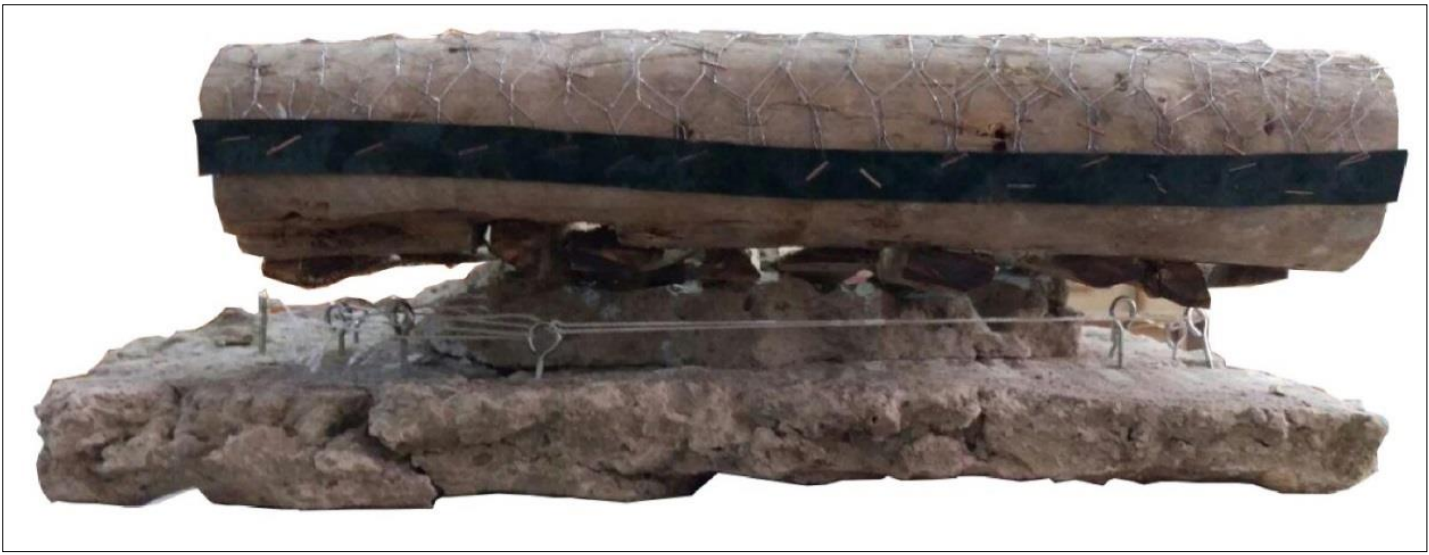

شكلثا: جينش لايههاى مورد استفاده با بازسازى لايه لمبه كوبى، لايه بستر و مسلحكردن لايه آستر با استفاده از قلابهاى كالوانيزه و سيم

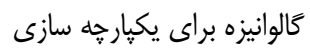

Fig. 4: The used layout of the layers with reconstruction of the lamellar layer, liner layer and reinforcing the liner layer using galvanized hooks and wire for integration

(شكلهاى \و ^). در هر مرحله از سوراخ كارى با استفاده

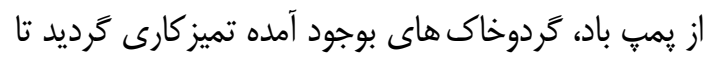
محفظه جهت اتصـال ميخ هاى كَّى با لايههاى آسـتر و و

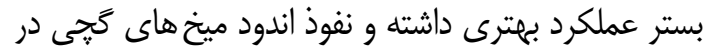

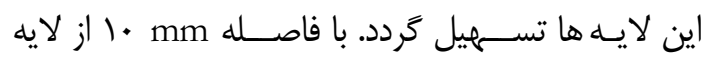

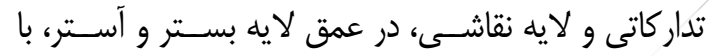

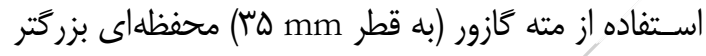
از قطر مته كَردبر بهصورت كاملا محتاطانه ايجاد كرديد. اين محفظه براى اتصال بهتر ميخ گَّى در كَترهاى

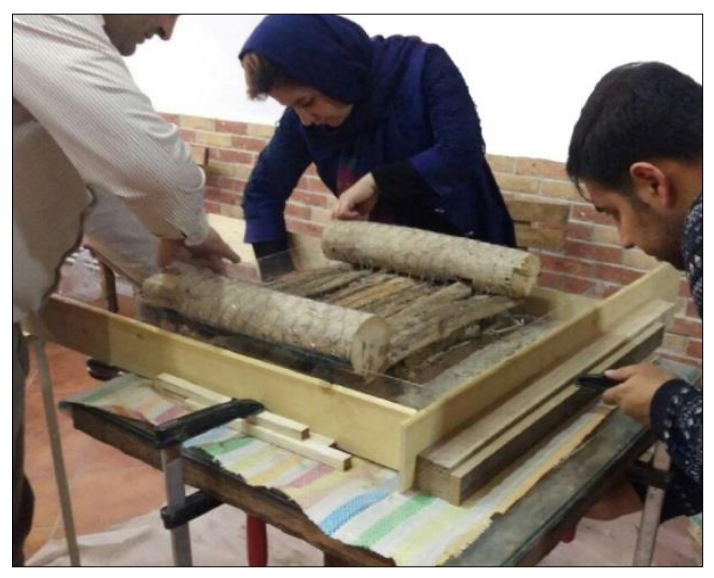

شكل ه: قالببندى نمونه اجرايى با لايههاى تيرهاى جوبى و لمبه كوبى، آستر و بستر

Fig. 5: Formatting an implemented specimen with layers of wooden beams and substrate and liners

१९

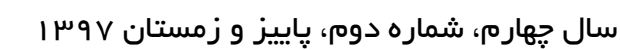

با جينش لايه هاى بستر و لمبه كوبى بر روى تيرهاى



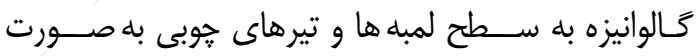

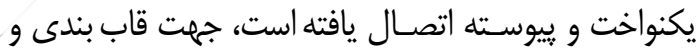

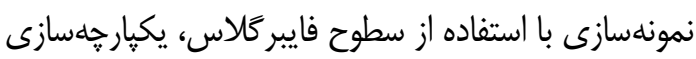

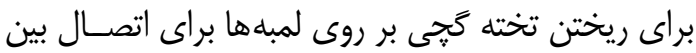

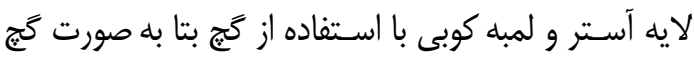

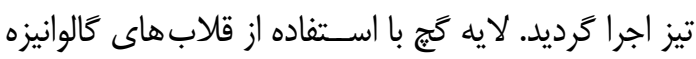



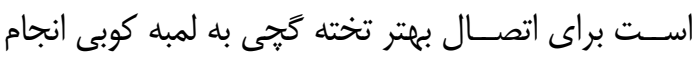

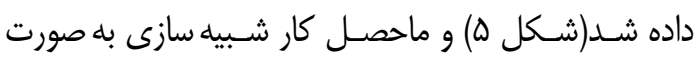

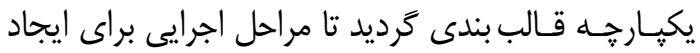

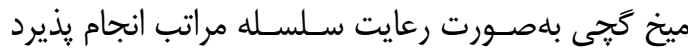

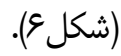
مرحله بعدى مشخص نمودن محل ميخ هاى كَّى است.

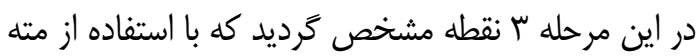

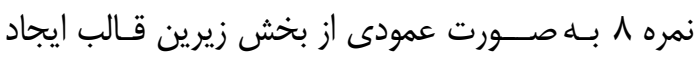

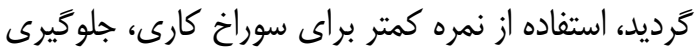

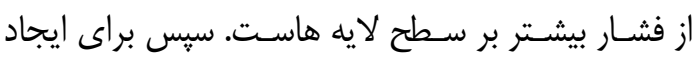

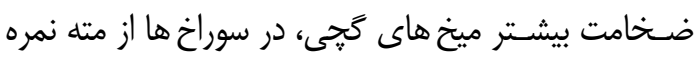

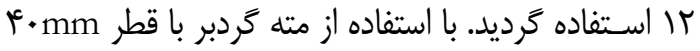

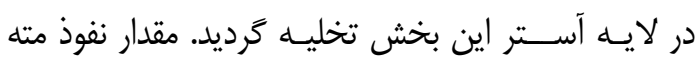




بيشـتر، بلهـورت شـكل نعلبكى ايجاد شــدهاسـت. نفوذ

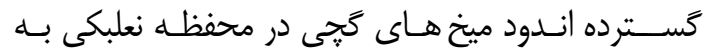

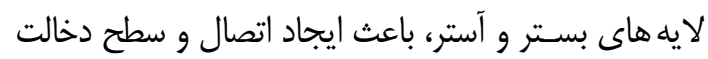

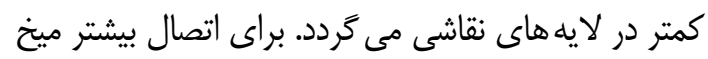

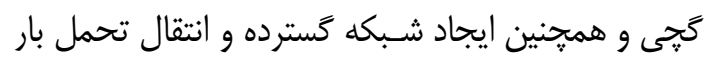

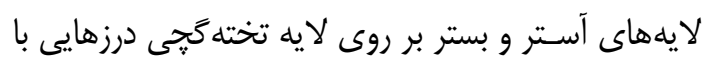

زاويه هأ درجه بر محفظه عمودى ايجاد شد (شكل 9)

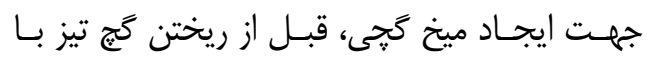

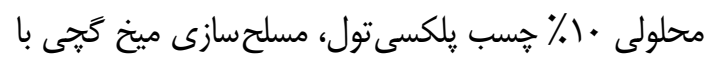



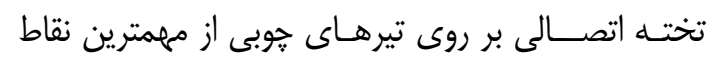

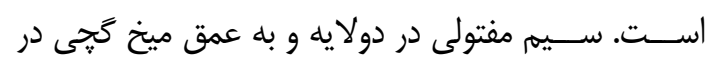

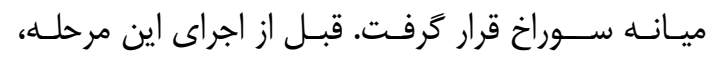

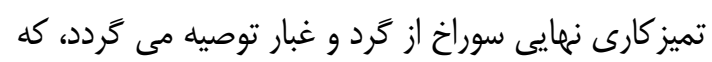

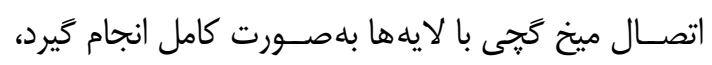

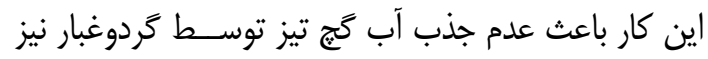

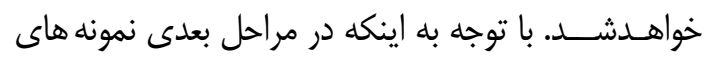

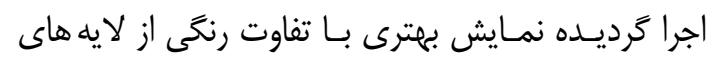

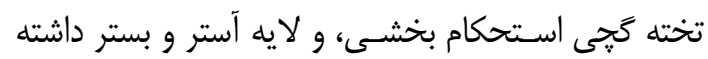

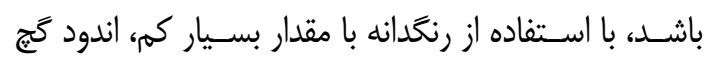

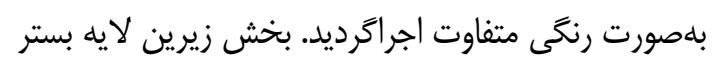

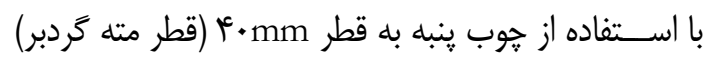
يوشانده شد، اين عمل براى جلوَيرى از ريخته شدن اندود

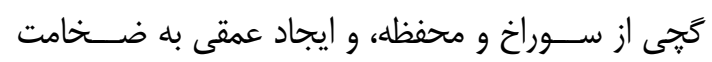

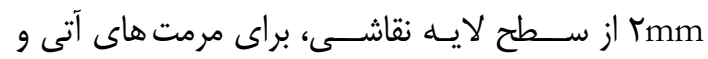
نمايش محل دخالت هاى انجام مى گيرد. كَّ مورد استفاده

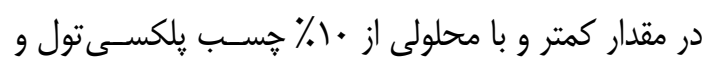

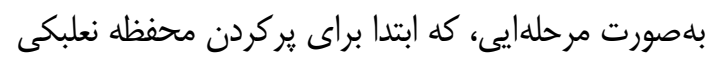

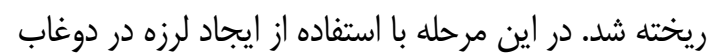

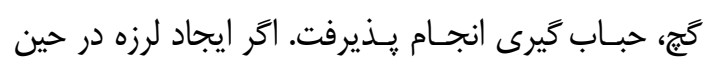

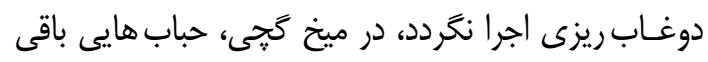

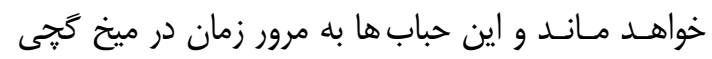

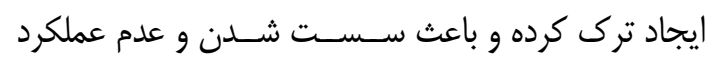

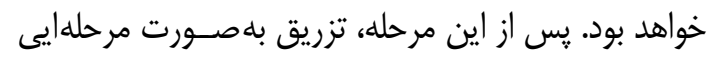

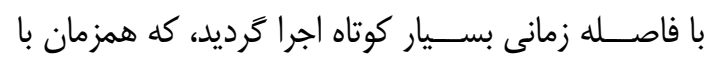
تزريق، لرزش نيز انجام مىيذيرد. با با بام

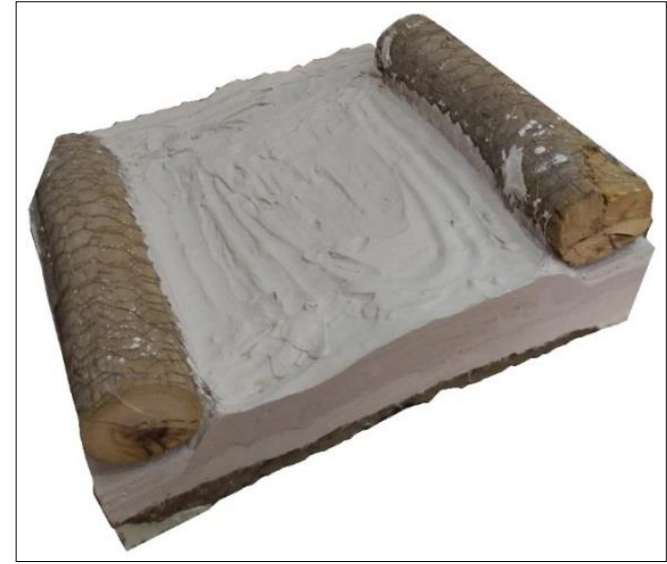

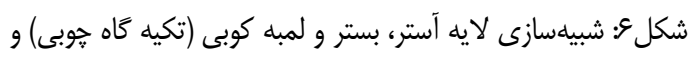

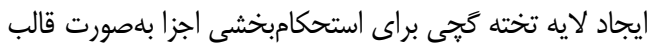
گيرى شده

Fig. 6: Simulation of the liners, substrate and lamellar layers with wooden beams and create a layer of plaster boards to strengthen the molded components

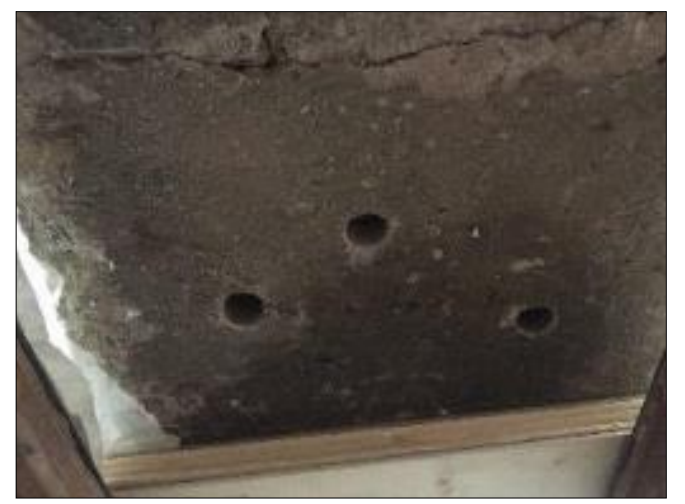

شكل V: سوراخهاى ايجاد كرديده بر سطح زيرين نمونه شبيدسازى شده با استفاده از مته كَردبر

Fig. 7: The holes created on the surface of the plasterboard layer of the simulated sample

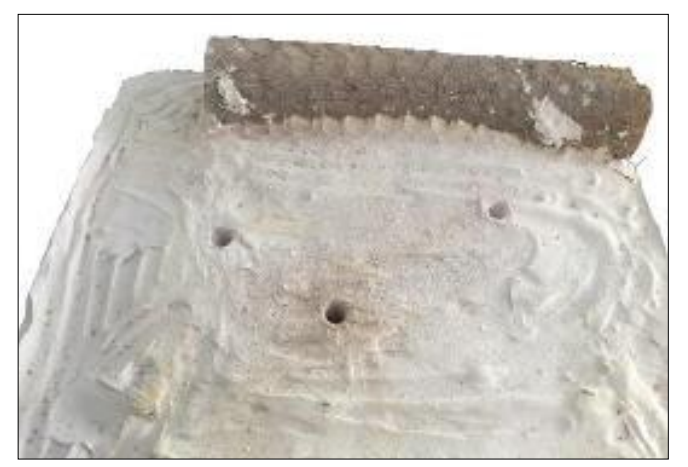

شكلم: سوراخهاى ايجاد گَريده بر سطح لايه تخته گَّى نمونه شبيهسازى شده

Fig. 8: Holes created on the bottom of the simulated sample using a gimlet drill 


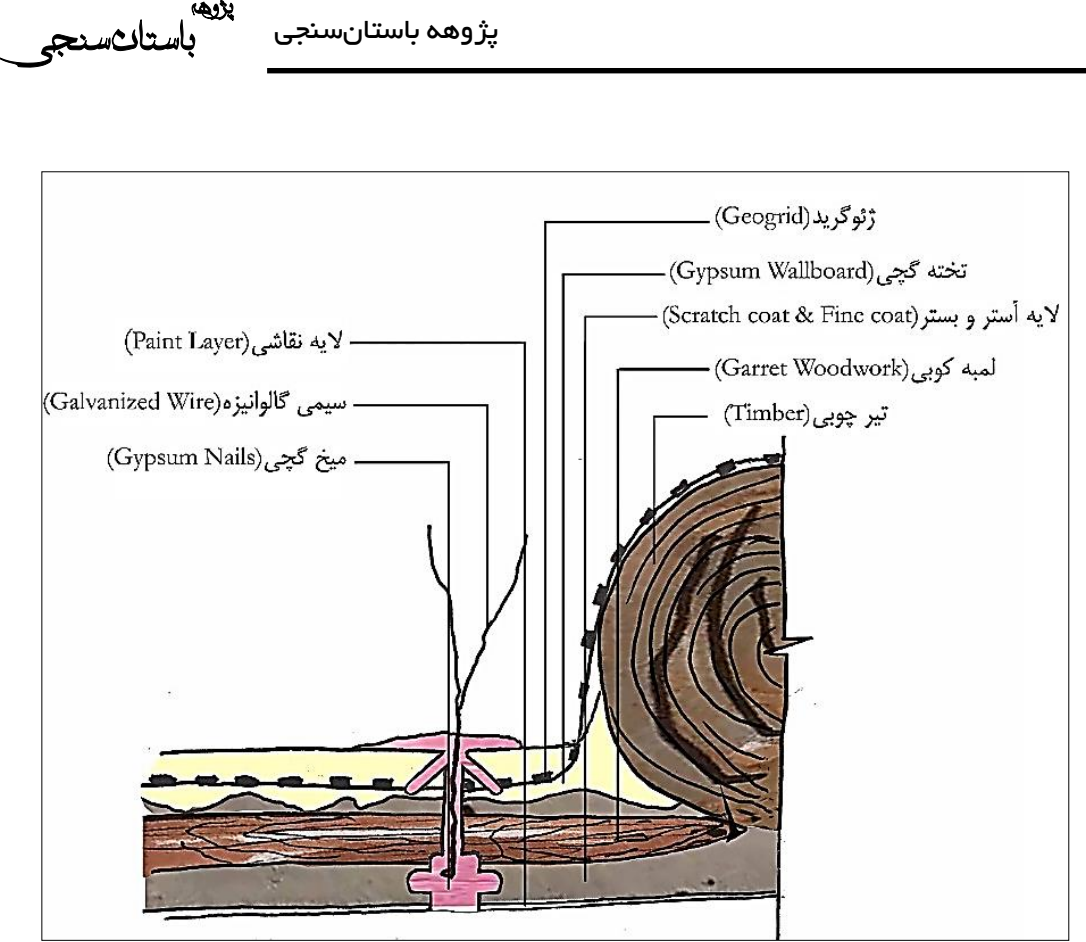

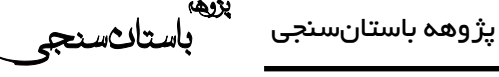

شكلج: ديتايل لايه هاى تكيه كَاه، بستر

و آستر و روش ييشنهادى براى اجرا

Fig. 9: Datasheets of the supporting, substrate and liner layers and the proposed method for implementation
درگيرى بيشــتر بـا لايه محافظ تخته گُجى بر روى لمبه

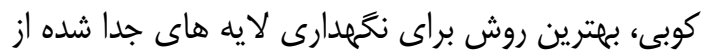

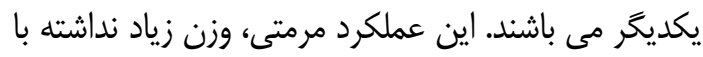

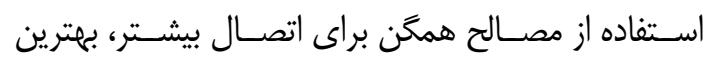
راهكار است. اين ييشنهاد تنها براى يوشش ها كاربرد دارد، و بايد لايه تخته كَجى مسـلح براى اسـتحكام بخشـى در ميانه تيريوش ها بر ســطح لمبه كوبى، بين لايه بســـتر و

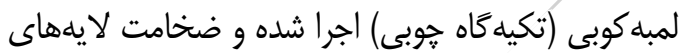

اتمام كار شبيه سازى يوشش، يكى از ميخ هاى گَّى براى

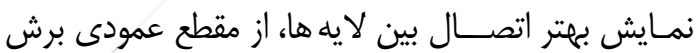
داده شـد تا شكل كلى ميخ گَجى با كستره نفوذ اندود گَج



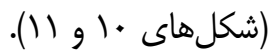
اجراى ميخ هـاى گَجى در يشـــت لايه نقاشــى در

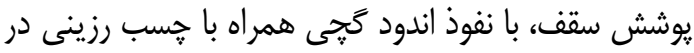

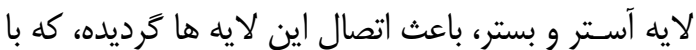

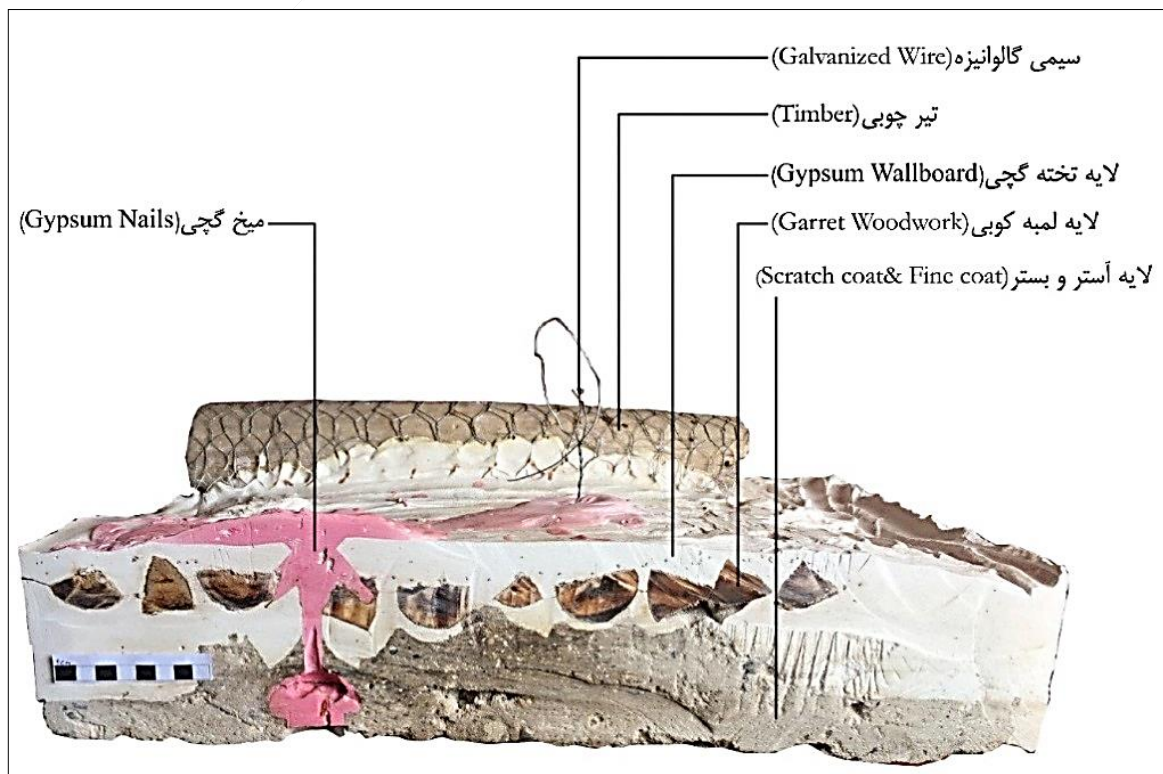

شكل • (: سطح مقطع از نمونه شبيه سازى شده كه ميخ گَّى با رنخ متفاوت ايجاد گرديده است

Fig. 10: The cross-sectional area of the simulated sample created with plaster nail with a different color 


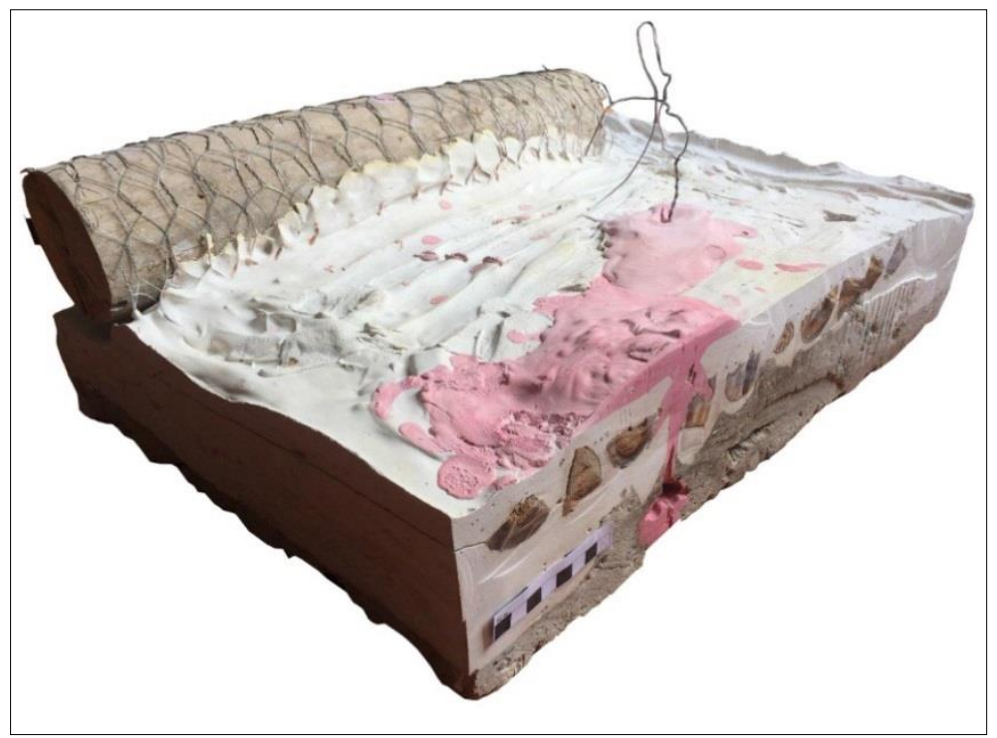

شكل | (ا: برش ايزومتريك از نمونه شبيهسازى شده (لايهها) به همراه سيم مفتولى براى مسلح كردن ميخ گَّى

Fig. 11: Isometric slabs of substrate, liner and lamellar layers for strengthening and created plaster nail along with a wire for reinforcing the plaster nail

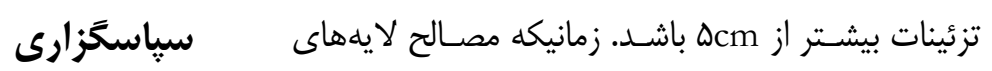

نغارندكان بر خود لازم مى دانند از اعضــاء آموزشــاه آزاد

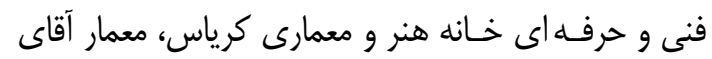

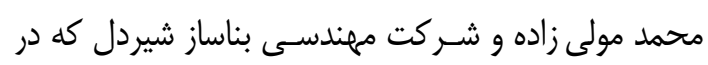

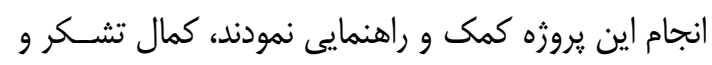
قدردانى را به جاى آورند.

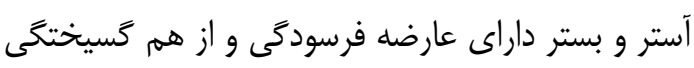



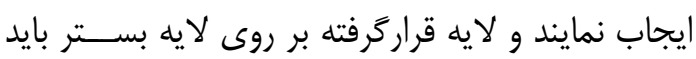

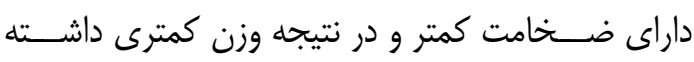
باشد. 